\title{
Seismic behaviour of prestressed and normal reinforcement of communication tower with ultra-high performance concrete, high strength concrete and normal concrete materials
}

\begin{abstract}
Nowadays, advances in telecommunications and broadcasting have led to the implementation of communication towers for installing network equipment. These towers are designed to go as high as possible in order to cover large area and avoid obstructions. However, there exist many challenges faced by engineers in relation to design of the tall and slender structures such as the complexity configuration of the structure. The nonlinear dynamic analysis is the only method that describes the actual behaviour of a structure during earthquake. Therefore, this study aims to investigate the behaviour of ultra-high performance concrete (UHPFC), high-strength concrete (HSC) and normal concrete communication tower with $30 \mathrm{~m}$ height located in Malaysia under seismic excitation. Also, to provide strength, stiffness and stability for the slender structures due to their sensitivity to dynamic load such as earthquake and vibration forces. For this propose, the finite element model of the tower is developed and time history analysis of communication tower under seismic load was conducted. In addition, the effect of using prestress instead of conventional reinforcement was investigated. The result indicated that prestressing of tower had lesser effect on the lateral displacement of tower under earthquake excitation. Although, the tower with UHPFC and HSC material shows lower lateral peak displacement against earthquake load compared to the normal concrete, which led to the increase in the use of these materials in lateral stiffness of the tower structure.
\end{abstract}

Keyword: Communication towers; Ultra-high performance concrete (UHPFC); Highstrength concrete (HSC); Dynamic nonlinear analysis; Finite element analysis; Prestressed concrete 